\title{
Effects of changing the supply of nitrogen and phosphorus on growth and interactions between Eucalyptus globulus and Acacia mearnsii in a pot trial
}

\author{
David I. Forrester ${ }^{1,2,3,8}$, Annette L. Cowie ${ }^{2,4}$, Jürgen Bauhus ${ }^{2,5}$, Jeff T. Wood ${ }^{6}$ \& \\ Robert I. Forrester ${ }^{7}$ \\ ${ }^{1}$ School of Resources, Environment and Society, The Australian National University, ACT 0200, Canberra, \\ Australia. ${ }^{2}$ Cooperative Research Centre for Greenhouse Accounting, GPO Box 475, ACT 2601, Canberra, \\ Australia. ${ }^{3}$ School of Forest and Ecosystem Science, The University of Melbourne, PO Box 137, VIC 3084, \\ Heidelberg, Australia. ${ }^{4}$ NSW Department of Primary Industries, PO Box 100, NSW 2119, Beecroft, \\ Australia. ${ }^{5}$ Institute of Silviculture, University of Freiburg, Tennenbacherstr. 4, 79106, Freiburg, Germany. \\ ${ }^{6}$ Statistical Consulting Unit, The Graduate School, The Australian National University, ACT 0200, Canberra, \\ Australia. ${ }^{7}$ Kambah, ACT 2902, Canberra, Australia. ${ }^{8}$ Corresponding author*
}

Received 31 July 2005. Accepted in revised form 15 September 2005

Key words: Acacia mearnsii, competition, Eucalyptus globulus, facilitation, mixed-species

\begin{abstract}
Significant increases in aboveground biomass production have been observed in mixed plantations of Eucalyptus globulus and Acacia mearnsii when compared to monocultures. However, this positive growth response may be enhanced or lost with changes in resource availability. Therefore this study examined the effect of the commonly limiting resources soil N, P and moisture on the growth of E. globulus and A. mearnsii mixtures in a pot trial. Pots containing two E. globulus plants, two $A$. mearnsii plants or one of each species were treated with high and low levels of $\mathrm{N}$ and $\mathrm{P}$ fertiliser. After 50 weeks, E. globulus plants grew more aboveground biomass in mixtures than monocultures. A. mearnsii were larger in mixtures only at low $\mathrm{N}$, where both species were similar in size and the combined aboveground biomass of both species in mixture was greater than that of monocultures. At high $\mathrm{N}$ and both high and low levels of $\mathrm{P}$ fertiliser E. globulus appeared to dominate and suppress A. mearnsii. In these treatments, the faster growth of E. globulus in mixture did not compensate the reduced growth of A. mearnsii, so mixtures were less productive than (or not significantly different from) E. globulus monocultures. The greater competitiveness of E. globulus in these situations may have resulted from its higher $\mathrm{N}$ and $\mathrm{P}$ use efficiency and greater growth response to $\mathrm{N}$ and $\mathrm{P}$ fertilisers compared to $A$. mearnsii. This trial indicates that the complex interactions between species in mixtures, and thus the success of mixed plantations, can be strongly influenced by site factors such as the availability of $\mathrm{N}$ and $\mathrm{P}$.
\end{abstract}

\section{Introduction}

The aboveground biomass or volume of different species combinations have been compared with monocultures in many studies, and mixtures have been found to have higher, lower or the same

\footnotetext{
*FAX No: + 61-3-9450 8644.

E-mail: davidif@unimelb.edu.au
}

productivity compared with monocultures (Cannell et al., 1992; FAO, 1992). Site factors such as soil N, P and moisture availability can also influence the growth of mixtures relative to monocultures, so mixtures are likely to be more productive than monocultures on some sites but not on others (Assmann, 1970; DeBell et al., 1987; FAO, 1992; Fredericksen et al., 1993; West, 1991). 
Facilitation interactions between species in mixtures generally predominate where resources are in low supply, under high-physical stress or high-consumer pressure (Bertness and Callaway, 1994; Holmgren et al., 1997). The dominance of competition increases towards the more productive end of the environmental gradient, where physical stress or consumer pressures are low (Bertness and Callaway, 1994; Holmgren et al., 1997). Thus facilitative interactions in mixed stands will only increase yields if there is a limited supply of the resource for which acquisition was facilitated or competition was reduced, such that the effect of these positive interactions outweighs the negative, competitive effects. The influence of site factors such as soil $\mathrm{N}$ and $\mathrm{P}$ availability on the productivity and the interactions and processes in mixtures of tree species is not well understood. However, this information is vital when establishing mixed species plantations.

It would be very costly and time consuming to examine the performance of species in mixtures under the full range of field site conditions. Here, a pot trial was used to examine the effect of soil N, P and moisture on the growth of E. globulus and $A$. mearnsii mixtures. These factors often limit the growth of plantations in Australia.

\section{Materials and methods}

\section{Species selection and seed source}

E. globulus and A. mearnsii were used because mixtures of these species have produced significantly higher quantities of aboveground biomass than monocultures in a field trial (Bauhus et al., 2004; Forrester et al., 2004). The seed of both species was purchased from the Australian Tree Seed Centre of CSIRO Forestry and Forest Products in Canberra (Seedlot numbers 18891 and 16265 for E. globulus and A. mearnsii, respectively).

\section{Experimental design and treatments}

The experiment consisted of a $3 \times 2 \times 2 \times 3$ factorial design containing 3 species combinations, 2 levels of $\mathrm{P}$ fertiliser, 2 levels of $\mathrm{N}$ fertiliser and 3 levels of watering. These treatment combinations were replicated twice in two blocks and the spatial distribution of pots within the replicates was randomised. The effective replication within this factorial design for each species combination, nutrient level and water level was 36, 24 and 36, respectively. The interactions between the factors were of particular interest and thus a factorial design provided an efficient way of studying this in a single experiment. The factorial design (see Cochran and Cox, 1957; Williams et al., 2002) allowed the examination of all interactions between factors, as opposed to separate experiments that would not have allowed such an examination.

Each pot contained two plants: two E. globulus (EE), two A. mearnsii (AA) or one of each species (EA). Phosphorus was supplied as triple superphosphate at initial low and high rates of $20 \mathrm{mg} \mathrm{P} \mathrm{kg}{ }^{-1}$ soil (low P) and $200 \mathrm{mg} \mathrm{P} \mathrm{kg}^{-1}$ soil (high P). Nitrogen was supplied as ammonium nitrate at initial low and high rates of $60 \mathrm{mg} \mathrm{N} \mathrm{kg}^{-1}$ soil (low $\mathrm{N}$ ) and $600 \mathrm{mg} \mathrm{N} \mathrm{kg}{ }^{-1}$ (high $\mathrm{N}$ ). These rates were determined after testing these species in this particular soil, to ensure that the high rates were not toxic nor induced salt stress. Additional fertiliser applications were required to maintain the high $\mathrm{N}$ and $\mathrm{P}$ availability and to prevent deaths in the low $\mathrm{N}$ treatment. Final application rates were 210 and $900 \mathrm{mg} \mathrm{N} \mathrm{kg}^{-1}$ soil in the low and high $\mathrm{N}$ treatments respectively, and 20 and $267 \mathrm{mg} \mathrm{P} \mathrm{kg}^{-1}$ soil in the low and high $\mathrm{P}$ treatments respectively. Other nutrients and micronutrients were added to all treatments at the following rates (all in $\mathrm{mg} \mathrm{kg}^{-1}$ soil): $365 \mathrm{~K}, 148 \mathrm{~S}, 21 \mathrm{Mg}, 22 \mathrm{Fe}$, $8 \mathrm{Cu}, 8 \mathrm{Zn}, 2 \mathrm{~B}$ and $1 \mathrm{Mo}$. The initial fertiliser was applied by mixing into the potting medium when preparing the medium $(2: 1$ coarse river sand and subsoil). Subsoil was obtained from the glasshouse facility site at The Australian National University, Canberra, Australia, and was sieved (6 $\mathrm{mm}$ mesh) before mixing. This substrate had a low total $\mathrm{N}\left(80 \mathrm{mg} \mathrm{kg}^{-1}\right)$ and $\mathrm{P}$ availability (Bray $1 \mathrm{P} 17 \mathrm{mg} \mathrm{kg}^{-1}$ ). More detail about soil nutrition is provided in Forrester (2004).

Water was applied at three levels: high, medium and low. Plants receiving the high and medium treatment were watered three times and once a week, respectively. Those receiving the low treatment were only watered when one of 
the plants showed signs of water stress (wilting). On the specified days water was applied until it started to seep out of the bottom of the pot.

\section{Seed propagation and seedling establishment}

Seedlings were grown in $11 \mathrm{~cm}$ diameter pots (12 cm deep) containing the 2:1 coarse river sand and subsoil medium until the experiment began. A. mearnsii seedlings were inoculated with a soil slurry to provide Rhizobia spores. The slurry was made from soil taken from a 5-yearold A. mearnsii tree in Canberra, ACT, and a 10-year-old $A$. mearnsii tree near Ulladulla, NSW, and consisted of about $250 \mathrm{~g}$ of soil in 9 liters of water. After 5 months seedlings (up to $40 \mathrm{~cm}$ tall) were transplanted into $75-1$ pots ("Easy lift" planter bags; $45 \mathrm{~cm}$ diameter and $50 \mathrm{~cm}$ deep). At this stage all A. mearnsii seedlings were nodulated.

Plants were grown in a glasshouse until week 14, when they reached a height that required them to be moved outside. The spatial pattern was maintained outside but the spacing between pots was increased to reduce shading so that there was $50 \mathrm{~cm}$ between pots within rows and $1.5 \mathrm{~m}$ between rows. Plastic weed mats and plastic collars were used to prevent any root growth into the soil beneath the pots (an additional nutrient source), and to prevent rain from watering the plants, respectively.

\section{Data collection}

Stem diameter and plant heights were measured fortnightly from the day after the seedlings were transplanted into the pots until the plants were harvested at the end of the experiment (50 weeks later). Diameters were measured at a point $10 \mathrm{~cm}$ above the soil surface $\left(D_{10}\right)$ to avoid the swelling at the root collar of E. globulus.

To estimate aboveground biomass of plants prior to the destructive sampling at week 50, allometric biomass equations were developed between aboveground biomass and diameter $\left(D_{10}\right.$; in $\left.\mathrm{mm}\right)$ at the end of the experiment. These equations were used to estimate aboveground biomass from fortnightly diameter measurements. There was no significant treatment effect on the relationship between biomass and diameter for E. globulus but for A. mearnsii there was a signif- icant $\mathrm{P}$ effect. Including height as an explanatory variable did not improve the models.

\section{E. globulus}

$$
\begin{aligned}
& \text { Ln aboveground biomass }(\mathrm{g}) \\
& =-1.646+2.4124 \mathrm{Ln}\left(\mathrm{D}_{10} ; \mathrm{mm}\right) \\
& \quad\left(\mathrm{P}<0.001, \text { Adj } \mathrm{R}^{2}=0.903\right)
\end{aligned}
$$

A. mearnsii

$$
\begin{aligned}
& \text { low } \mathrm{P} \text { Ln aboveground biomass }(\mathrm{g}) \\
& =-0.457+2.114 \mathrm{Ln}\left(\mathrm{D}_{10} ; \mathrm{mm}\right) \\
& \text { high } \mathrm{P} \text { Ln aboveground biomass }(\mathrm{g}) \\
& =-3.137+2.863 \mathrm{Ln}\left(\mathrm{D}_{10} ; \mathrm{mm}\right) \\
& \quad\left(\mathrm{P}<0.001, \text { Adj } \mathrm{R}^{2}=0.825\right)
\end{aligned}
$$

At the end of the growing period, each plant was harvested and the oven dry weight $\left(60^{\circ} \mathrm{C}\right.$ for 2 weeks) of the following components was recorded: stem, branch, foliage, fine-roots $(<2 \mathrm{~mm})$, medium roots $(>2 \mathrm{~mm}$ and $<5 \mathrm{~mm}$ ) and coarse roots $(>5 \mathrm{~mm})$. All roots were washed from the soil and detached fine-roots were collected by flotation.

Nitrogen and $\mathrm{P}$ concentrations were determined for each plant part except coarse roots. Coarse root and stems were assumed to have the same $\mathrm{N}$ and $\mathrm{P}$ concentrations so only stem samples were analysed. Soil was sampled from the middle of each pot. To determine $\mathrm{N}$ and $\mathrm{P}$ concentrations, ground and dried plant or soil material was digested in acid (potassium sulphate dissolved in concentrated sulphuric acid) and hydrogen peroxide (modified from Heffernan, 1985). For soil samples, $1 \mathrm{ml}$ of a copper sulphate solution catalyst was added to the soil for $12 \mathrm{~h}$ prior to the digestion. Total $\mathrm{N}$ and $\mathrm{P}$ were determined simultaneously in a continuous flow system (Technicon ${ }^{\circledR}$ TRAACS $800^{\mathrm{TM}}$ or Technicon Auto-Analyser II) using an ascorbic acid/ ammonium molybdate method.

\section{Calculations and statistical techniques}

Many indices have been used to describe the growth outcome of mixed-species systems and all have advantages and disadvantages (Jolliffe, 2000; Williams and McCarthy, 2001). A frequently used index and the only one used in this study is the relative yield (RY) of aboveground biomass Harper (1977): 
$\mathrm{RY}$ of species $\mathrm{A}=\frac{\text { yield of species } \mathrm{A} \text { in mixture }}{\text { yield of species A in monoculture }}$

(Harper 1977)

Regression relationships between diameter at $10 \mathrm{~cm}$ and aboveground biomass were fitted using GenStat ${ }^{\mathrm{TM}}$ (VSN International Ltd, Hemel Hemestead, U.K.). Due to an uneven distribution of residuals both variables were transformed using natural logarithms.

Treatment effects were tested using an Analysis of Variance (ANOVA) in GenStat ${ }^{\mathrm{TM}}$ (VSN International Ltd, Hemel Hemestead, U.K.). The Standard Errors of Difference (S.E.D.s) for comparison of treatment means are provided. Natural logarithmic or square root transformations were required for some variables to remove heteroskedasticity. In these cases, 95\% confidence intervals are provided. The tables contain the S.E.D.'s for the main effects and for interactions between the factors in the given table.

Comparisons between species and the effect of different species proportions (EE, EA and AA) were examined using the factors "monoculture", "mixmono" and "species": "monoculture" compares EE to AA, "mixmono" compares EA to EE or AA and "species" compares the E. globulus and A. mearnsii in EA.

Due to the large number of effects and variables examined, the following sections focus on the most important effects. These include interactions between $\mathrm{N}$, species proportions and species. Other important interactions include lower order interactions between two of these factors and the effects of $\mathrm{N}, \mathrm{P}$ and species proportion alone.

\section{Results}

\section{Biomass}

All treatments had a significant effect on plant biomass after 50 weeks. For detail on all the significant effects see Forrester (2004). In most cases, water effects were only significant when interacting with other factors, so to reduce the complexity of the discussion they are not described further. Different components of biomass were similarly affected by the treatments.
At low $\mathrm{N}$, both species grew more aboveground biomass in the mixed EA than EE or AA, and total pot aboveground biomass was higher in EA than EE or AA (Table 1). At high $\mathrm{N}$ E. globulus still grew larger in EA than EE but A. mearnsii were smaller in EA than AA and total pot aboveground biomass was higher in EE and EA than in AA. E. globulus aboveground biomass was greater in EA than EE at high $\mathrm{P}$, but $A$. mearnsii growth was not significantly different in EA to AA at either level of P. At both levels of $\mathrm{P}$, total pot aboveground biomass was not significantly different between EA and EE but both were higher than AA. At high $\mathrm{N}$ and $\mathrm{P}$, A. mearnsii was smaller than E. globulus and the increased growth of E. globulus in EA did not compensate for the smaller size of $A$. mearnsii.

Species proportion and fertiliser significantly influenced aboveground biomass as early as week 20. For E. globulus, these early effects followed the same trends as those at 50 weeks. However, for $A$. mearnsii, the effects of $\mathrm{N}$ on the species proportion were reversed, such that $A$. mearnsii were larger in terms of aboveground biomass in EA than AA at high $\mathrm{N}$, but smaller at low $\mathrm{N}$. This increase in growth in EA compared to EE or AA was shown using the RY of aboveground biomass in Figure 1.

The response of E. globulus to $\mathrm{N}$ and $\mathrm{P}$ fertiliser was greater than the response of $A$. mearnsii (Table 1). For example in EE, E. globulus aboveground biomass more than doubled, from $363 \mathrm{~g}$

Table 1. Aboveground biomass (g) of E. globulus and A. mearnsii in mixtures and monocultures at high and low levels of $\mathrm{N}$ and $\mathrm{P}$ fertiliser

\begin{tabular}{lllc}
\hline \multirow{2}{*}{ Fertiliser } & Species proportion & \multicolumn{2}{c}{ Aboveground biomass } \\
\cline { 3 - 4 } & & A. mearnsii & E. globulus \\
\hline \multirow{2}{*}{ Low P } & Monoculture & 486 & 591 \\
& Mixture & 495 & 687 \\
High P & Monoculture & 236 & 668 \\
& Mixture & 243 & 1140 \\
Low N & Monoculture & 348 & 363 \\
& Mixture & 461 & 498 \\
High N & Monoculture & 375 & 896 \\
& Mixture & 277 & 1329 \\
\hline
\end{tabular}

Standard error of difference $=72$ (not for $\mathrm{N}$ versus $\mathrm{P}$ comparisons). 

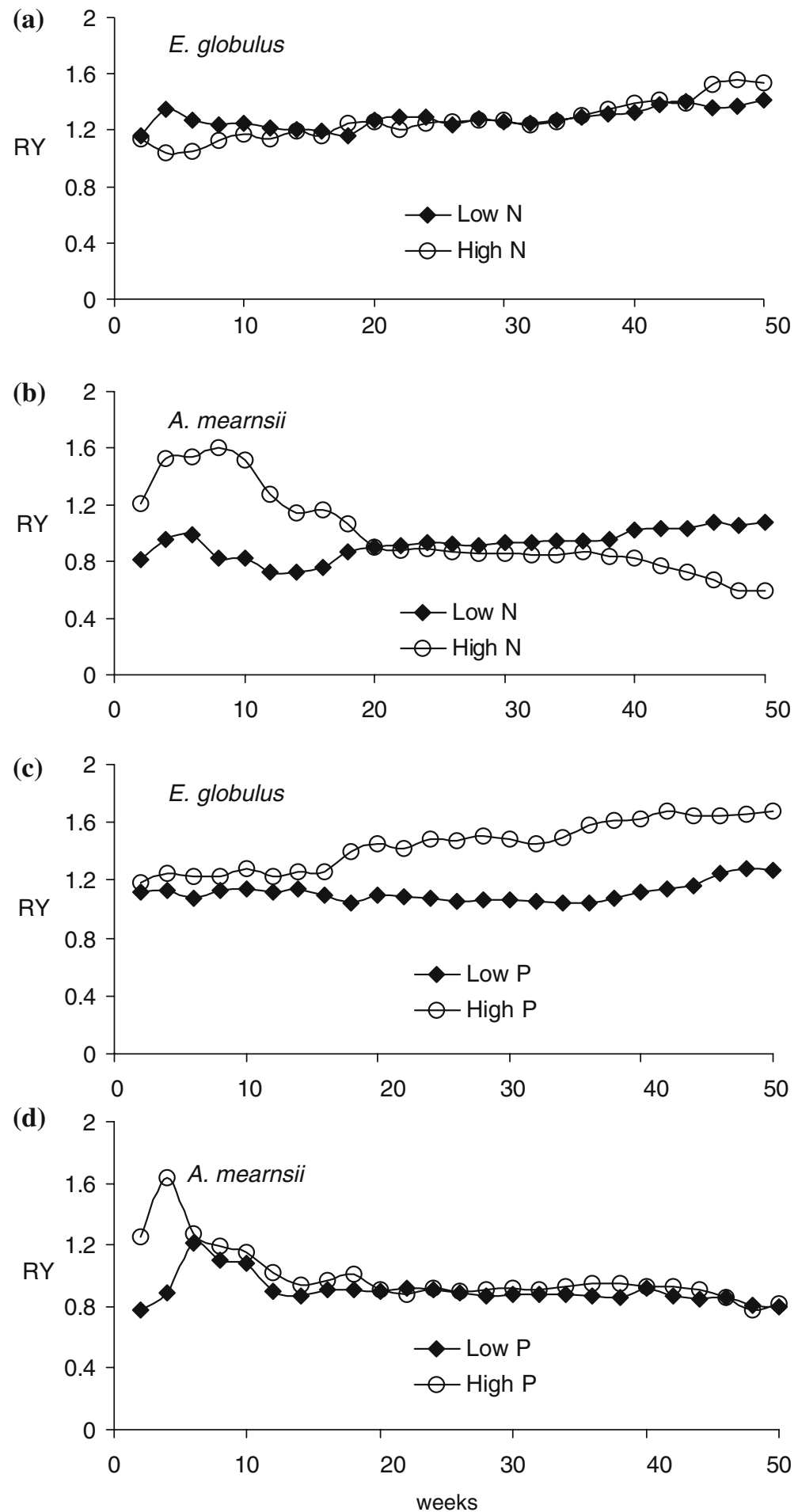

Figure 1. Relative yield (RY) of aboveground biomass for (a) E. globulus at low and high levels of N, (b) A. mearnsii at low and high levels of N, (c) E. globulus at low and high levels of P and (d) A. mearnsii at low and high levels of P. A RY of 1 indicates that plants were the same size in mixture as in monoculture. RY $<1$ indicates that plants were smaller in mixture than in monoculture and RY $>1$ indicates that plants were larger in mixture than in monoculture. 
Table 2. Root: shoot ratio of Eucalyptus globulus and Acacia mearnsii in mixtures and monocultures at high and low levels of $\mathrm{N}$ and $\mathrm{P}$ fertiliser

\begin{tabular}{llll}
\hline Fertiliser & Species proportion & A. mearnsii & E. globulus \\
\hline \multirow{2}{*}{ Low P } & Monoculture & 0.38 & 0.48 \\
& Mixture & 0.35 & 0.49 \\
\multirow{2}{*}{ High P } & Monoculture & 0.37 & 0.51 \\
& Mixture & 0.22 & 0.54 \\
Low N & Monoculture & 0.29 & 0.62 \\
& Mixture & 0.26 & 0.65 \\
High N & Monoculture & 0.46 & 0.38 \\
& Mixture & 0.31 & 0.37
\end{tabular}

Standard error of difference $=0.033$ (not for $\mathrm{N}$ versus $\mathrm{P}$ comparisons).

Table 3. The total soil $\mathrm{N}$ and $\mathrm{P}\left(\mathrm{g} \operatorname{pot}^{-1}\right)$ in mixtures and monocultures at high and low levels of $\mathrm{N}$ and $\mathrm{P}$ fertiliser at the end of the experiment

\begin{tabular}{llll}
\hline Fertiliser & AA & EA & EE \\
\hline Total soil N & & & \\
Low P & $5.7-10.4$ & $7.7-13.0$ & $7.2-12.3$ \\
High P & $3.0-6.5$ & $4.2-8.2$ & $4.3-8.4$ \\
Low N & $3.6-7.5$ & $5.0-9.4$ & $5.5-10.0$ \\
High N & $4.8-9.1$ & $6.7-11.6$ & $5.9-10.5$ \\
Total soil P & & & \\
Low P & $17.6-22.4$ & $17.3-22.0$ & $19.6-24.6$ \\
High P & $26.2-31.9$ & $27.8-33.8$ & $26.9-32.7$ \\
Low N & $21.8-27.0$ & $22.0-27.2$ & $24.8-30.5$ \\
High N & $21.6-26.8$ & $22.6-27.9$ & $21.4-26.7$ \\
\hline
\end{tabular}

Ranges are $95 \%$ confidence intervals. $\mathrm{EE}=$ E. globulus monoculture, $\mathrm{EA}=$ mixture, $\mathrm{AA}=A$. mearnsii monoculture.

at low $\mathrm{N}$ to $896 \mathrm{~g}$ at high $\mathrm{N}$. In AA, A. mearnsii aboveground biomass increased from $348 \mathrm{~g}$ at low $\mathrm{N}$ to $375 \mathrm{~g}$ at high $\mathrm{N}$.

The root: shoot $(\mathrm{R}: \mathrm{S})$ ratio was higher for E. globulus than A. mearnsii (Table 2). The R : S ratio was affected by an interaction between $\mathrm{N}$, species proportion and species and an interaction between $\mathrm{P}$, species proportion and species. The effect of $\mathrm{N}$ and $\mathrm{P}$ on the $\mathrm{R}: \mathrm{S}$ ratio was greater than the effect of species proportion. The effect of species proportion was only significant for A. mearnsii at high $\mathrm{N}$ and high $\mathrm{P}$ where the $\mathrm{R}: \mathrm{S}$ ratio was lower in EA than AA. High $\mathrm{N}$ reduced the $\mathrm{R}: \mathrm{S}$ ratio of E. globulus compared to low N. For A. mearnsii, the $\mathrm{R}: \mathrm{S}$ ratio declined at high $\mathrm{P}$ compared to low $\mathrm{P}$.
Table 4. Nitrogen in aboveground biomass (g) of Eucalyptus globulus and Acacia mearnsii in mixtures and monocultures after 50 weeks at high and low levels of $\mathrm{N}$ and $\mathrm{P}$ fertiliser

\begin{tabular}{llll}
\hline Fertiliser & Species proportion & A. mearnsii & E. globulus \\
\hline \multirow{2}{*}{ Low P } & Monoculture & 6.64 & 4.20 \\
& Mixture & 6.91 & 4.74 \\
\multirow{2}{*}{ High P } & Monoculture & 2.68 & 4.83 \\
& Mixture & 3.20 & 8.45 \\
Low N & Monoculture & 4.85 & 1.17 \\
& Mixture & 7.00 & 1.76 \\
High N & Monoculture & 4.48 & 7.86 \\
& Mixture & 3.11 & 11.43 \\
\hline
\end{tabular}

Standard error of difference $=0.96$ (not for $\mathrm{N}$ versus $\mathrm{P}$ comparisons)

Table 5. Phosphorus in aboveground biomass (g) of Eucalyptus globulus and Acacia mearnsii in mixtures and monocultures at high and low levels of $\mathrm{N}$ and $\mathrm{P}$ fertiliser

\begin{tabular}{llll}
\hline Fertiliser & Species proportion & A. mearnsii & E. globulus \\
\hline \multirow{2}{*}{ Low P } & Monoculture & $0.28-0.52$ & $0.25-0.46$ \\
& Mixture & $0.21-0.49$ & $0.28-0.66$ \\
\multirow{2}{*}{ High P } & Monoculture & $0.43-0.78$ & $0.46-0.85$ \\
& Mixture & $0.38-0.91$ & $0.70-1.78$ \\
Low N & Monoculture & $0.33-0.61$ & $0.22-0.41$ \\
& Mixture & $0.40-0.95$ & $0.31-0.74$ \\
High N & Monoculture & $0.35-0.66$ & $0.51-0.94$ \\
& Mixture & $0.20-0.47$ & $0.62-1.58$ \\
\hline
\end{tabular}

Ranges are $95 \%$ confidence intervals.

\section{Nitrogen and phosphorus in soils and plants}

There were no measurable differences in soil $\mathrm{N}$ contents between the two $\mathrm{N}$-fertilisation levels after 50 weeks (Table 3 ). In contrast, soil $\mathrm{P}$ was higher at high $\mathrm{P}$. Soil $\mathrm{N}$ was lower at high $\mathrm{P}$ than low P. There were no other significant treatments effects on soil $\mathrm{N}$ or $\mathrm{P}$ contents.

The total amount of $\mathrm{N}$ in aboveground biomass was affected by an interaction between $\mathrm{N}$, species proportion and species (Table 4). Nitrogen in $A$. mearnsii aboveground biomass was higher in EA than AA at low $\mathrm{N}$ but not significantly different at high N. However, N in E. globulus aboveground biomass was higher in EA than $\mathrm{EE}$ at high $\mathrm{N}$ but not significantly different at low $\mathrm{N}$. Aboveground $\mathrm{P}$ increased with $\mathrm{P}$ fertiliser but there were no interactions between $\mathrm{P}$, species proportion and species (Table 5). Nitrogen and $\mathrm{P}$ 
Table 6. Nitrogen and phosphorus ( $\mathrm{g}$ ) in plant biomass (above- and belowground biomass of both plants in a pot), and the percent of total system $\mathrm{N}$ or $\mathrm{P}$ ( $\mathrm{N}$ or $\mathrm{P}$ in soil and plant biomass) in plant biomass in mixtures and monocultures at high and low levels of $\mathrm{N}$ and $\mathrm{P}$ fertiliser

\begin{tabular}{|c|c|c|c|c|c|c|}
\hline \multicolumn{7}{|c|}{ Nitrogen and phosphorus (g) in plant biomass } \\
\hline \multirow[t]{2}{*}{ Fertiliser } & \multicolumn{3}{|c|}{ Nitrogen $($ SED $=1.0)$} & \multicolumn{3}{|c|}{ Phosphorus $($ SED $=0.17)$} \\
\hline & AA & EA & $\mathrm{EE}$ & AA & EA & $\mathrm{EE}$ \\
\hline Low $\mathrm{P}$ & 17.4 & 15.1 & 10.7 & 1.25 & 1.23 & 1.14 \\
\hline High P & 8.2 & 13.9 & 13.3 & 3.01 & 3.08 & 2.45 \\
\hline Low $\mathrm{N}$ & 13.4 & 11.2 & 3.6 & 1.81 & 2.07 & 1.31 \\
\hline High $N$ & 12.2 & 17.3 & 20.5 & 2.45 & 2.24 & 2.28 \\
\hline \multicolumn{7}{|c|}{ Percent of total system $\mathrm{N}$ or $\mathrm{P}$ in plant biomass } \\
\hline \multirow[t]{2}{*}{ Fertiliser } & \multicolumn{3}{|c|}{ Nitrogen $(\mathrm{SED}=4.81)$} & \multicolumn{3}{|c|}{ Phosphorus $(\mathrm{SED}=0.592)$} \\
\hline & AA & EA & $\mathrm{EE}$ & AA & EA & $\mathrm{EE}$ \\
\hline Low $\mathrm{P}$ & 69.6 & 61.5 & 47.9 & 5.97 & 5.95 & 5.51 \\
\hline High P & 63.7 & 67.2 & 58.1 & 9.19 & 9.02 & 7.70 \\
\hline Low N & 66.3 & 63.0 & 36.5 & 6.50 & 7.15 & 4.66 \\
\hline High N & 67.0 & 65.7 & 69.5 & 8.67 & 7.82 & 8.55 \\
\hline
\end{tabular}

$\mathrm{SED}=$ Standard error of difference (not for $\mathrm{N}$ versus $\mathrm{P}$ comparisons). $\mathrm{EE}=E$. globulus monoculture, $\mathrm{EA}=$ mixture, $\mathrm{AA}=$ A. mearnsii monoculture.

Table 7. Nitrogen use efficiency (aboveground biomass (g)/ nitrogen in aboveground plant biomass (g)) of Eucalyptus globulus and Acacia mearnsii in mixtures and monocultures at high and low levels of $\mathrm{N}$ and $\mathrm{P}$ fertiliser. Standard error of difference $=12.9$ (not for $\mathrm{N}$ versus $\mathrm{P}$ comparisons).

\begin{tabular}{llcl}
\hline Fertiliser & Species proportion & A. mearnsii & E. globulus \\
\hline \multirow{2}{*}{ Low P } & Monoculture & 77 & 222 \\
& Mixture & 78 & 210 \\
\multirow{2}{*}{ High P } & Monoculture & 120 & 210 \\
& Mixture & 104 & 202 \\
Low N & Monoculture & 99 & 316 \\
\multirow{2}{*}{ High N } & Mixture & 80 & 294 \\
& Monoculture & 98 & 117 \\
& Mixture & 102 & 119 \\
\hline
\end{tabular}

Standard error of difference $=12.9$ (not for $\mathrm{N}$ versus $\mathrm{P}$ comparisons).

interacted such that aboveground $\mathrm{N}$ was higher at high $\mathrm{P}$ than low $\mathrm{P}$ for E. globulus and vice versa for $A$. mearnsii (Tables 4 and 5). Nutrient contents were provided instead of nutrient concentrations so that uptake could be compared. Concentrations can be misleading when comparing plants of different sizes when large plants take up more nutrient but have lower foliar nutrient concentrations due to a dilution effect.

The $\mathrm{N}$ or $\mathrm{P}$ in the total plant biomass of a given pot (biomass of both plants in a pot aboveand belowground) was influenced by interactions
Table 8. Phosphorus use efficiency (aboveground biomass (g) phosphorus in aboveground plant biomass (g)) of Eucalyptus globulus and Acacia mearnsii in mixtures and monocultures at high and low levels of $\mathrm{N}$ and $\mathrm{P}$ fertiliser

\begin{tabular}{llcc}
\hline Fertiliser & Species proportion & A. mearnsii & E. globulus \\
\hline \multirow{2}{*}{ Low P } & Monoculture & $1089-1325$ & $1361-1652$ \\
& Mixture & $1173-1464$ & $1245-1553$ \\
High P & Monoculture & $219-266$ & $811-985$ \\
& Mixture & $230-287$ & $784-991$ \\
Low N & Monoculture & $486-589$ & $1013-1230$ \\
& Mixture & $498-621$ & $849-1059$ \\
High N & Monoculture & $492-598$ & $1090-1323$ \\
& Mixture & $542-677$ & $1149-1452$ \\
\hline
\end{tabular}

Ranges are $95 \%$ confidence intervals.

between $\mathrm{N}$ and species proportion and between $\mathrm{P}$ and species proportion (Table 6). The $\mathrm{N}$ in total plant biomass increased with the proportion of $A$. mearnsii (lowest at EE and highest at AA) at low $\mathrm{N}$ but increased with the proportion of E. globulus at high N. There was no significant difference in the total $\mathrm{P}$ in pot biomass between species proportions at low $\mathrm{P}$, but at high $\mathrm{P}$ the total $\mathrm{P}$ in pot biomass was lower in EE than EA or AA.

The proportion of $\mathrm{N}$ in the soil-plant system used by the plants was estimated as the proportion of the $\mathrm{N}$ in soil plus biomass (above- and 
belowground) that was in the biomass. The proportion of this total system $\mathrm{N}$ (plant and soil $\mathrm{N}$ ) held in the plant biomass was affected by an interaction between $\mathrm{N}$ and species proportion such that less than $40 \%$ of this $\mathrm{N}$ was in plant biomass in EE at low $\mathrm{N}$ but in all other species proportions at high and low $\mathrm{N}$ over $60 \%$ of total system $\mathrm{N}$ was in the plant biomass (Table 6). The proportion of total system $\mathrm{P}$ in plant biomass increased from low $\mathrm{P}$ to high $\mathrm{P}$ and from low $\mathrm{N}$ to high $\mathrm{N}$ (Table 6). There was a general increase in the proportion of total system $\mathrm{P}$ in plant biomass from EE to AA.

\section{Resource use efficiency}

Nitrogen and phosphorus use efficiency (grams of aboveground biomass per gram of $\mathrm{N}$ or $\mathrm{P}$ in aboveground biomass) was higher for E. globulus than A. mearnsii (Tables 7 and 8). Nitrogen use efficiency was higher at low $\mathrm{N}$ than at high $\mathrm{N}$ for E. globulus but not for A. mearnsii. Also, $\mathrm{P}$ use efficiency was higher at high $\mathrm{N}$ for $E$. globulus but not for $A$. mearnsii. Nitrogen use efficiency was higher at low $\mathrm{P}$ for E. globulus (although not significantly) but higher at high $\mathrm{P}$ for $A$. mearnsii. Phosphorus use efficiency was higher for both species at low $\mathrm{P}$ than high $\mathrm{P}$ (Table 8).

\section{Discussion}

The pot experiment showed that $\mathrm{N}$ and $\mathrm{P}$ supply have a strong influence on the growth of mixtures. E. globulus grew more aboveground biomass in EA than EE, whereas A. mearnsii was larger in EA than AA in most treatments (low $\mathrm{P}$, high $\mathrm{P}$ and low $\mathrm{N}$ ) but smaller at high $\mathrm{N}$. The positive growth response of E. globulus to growing in EA, as shown by the RY, was enhanced at high levels of $\mathrm{P}$ due to a reduction in competition from A. mearnsii.

\section{Effects of species proportion at low $N$}

At low $\mathrm{N}$, both species grew larger and produced more combined biomass in EA than EE or AA. Higher growth of E. globulus may have resulted from a higher $\mathrm{N}$ availability through either $\mathrm{N}$ fixation by $A$. mearnsii or accelerated $\mathrm{N}$ cycling.
Nitrogen in aboveground biomass was highest in AA and lowest in EE, suggesting a higher $\mathrm{N}$ availability with increasing proportions of A. mearnsii. Similarly, in published pot and field trials, increased growth of Eucalyptus species in mixture with $\mathrm{N}$-fixing tree species has resulted (at least in part) from higher $\mathrm{N}$ availability (Baker et al., 1994; Bauhus et al., 2004; Binkley et al., 1992a, 2003a; Boydon et al., 2005; Forrester et al., 2004; Khanna, 1997; Vezzanni et al., 2001).

Differences in resource availability can be associated with differences in biomass allocation, as plants allocate more biomass to obtain the resources that are limiting. Allocation belowground may decrease if aboveground competition for light increases, however an increase in competition for below ground resources (such as N) could have the opposite effect (Bloom et al., 1985). In this experiment, E. globulus allocated a higher proportion of biomass belowground (higher $\mathrm{R}$ : $\mathrm{S}$ ratio) at low $\mathrm{N}$ than high $\mathrm{N}$. However, there were no significant differences in allocation (no change in $\mathrm{R}: \mathrm{S}$ ratio) between species proportions for either species at low N. While $E$. globulus had significantly higher leaf areas than A. mearnsii (2.9 and $0.9 \mathrm{~m}^{2}$ respectively; Forrester 2004), E. globulus may have experienced less competition for light in EA than EE. In addition, the $\mathrm{N}$ supply for E. globulus appeared to be higher in EA than EE since $\mathrm{N}$ in aboveground biomass increased from EE to EA. The lack of change in the R:S ratio may be a combined effect of these two factors. A. mearnsii may have been larger in EA than AA due to reductions in competition for soil resources as evidenced by the higher $\mathrm{N}$ content of aboveground biomass of A. mearnsii in EA than AA.

Interspecific competition can be lower in mixtures than intraspecific competition in monocultures, when there is some differentiation of resource use (Kelty and Cameron, 1995; Vandermeer, 1989). Resource differentiation may have reduced the competition between $A$. mearnsii and E. globulus in EA such that a higher proportion of the nutrient might have been utilised in EA than AA or EE. This was quantified by measuring the total $\mathrm{N}$ or $\mathrm{P}$ in plant biomass and soil, and calculating the proportion of the sum (nutrient in plant biomass + nutrient in soil) that was in plant biomass. While not significant, the proportion of $\mathrm{N}$ and $\mathrm{P}$ in plant 
biomass was higher in treatments with acacias in most cases (except at high $\mathrm{N}$ ), and more accurate measurements (a higher number of samples per pot) may have shown significant treatment effects. This finding is supported by other studies that have shown that $\mathrm{N}$-fixing species cannot only increase $\mathrm{N}$ resources but also increase the overall $\mathrm{P}$ availability. For example, soil $\mathrm{P}$ concentrations declined with increasing proportions of Facaltaria moluccana in mixture with E. saligna at 17 years (Binkley et al., 2000; Kaye et al., 2000) however, more $\mathrm{P}$ was cycled through litterfall in stands with F. moluccana (Binkley et al., 1992a) at age 6 years. Here, the N-fixer appeared to be capable of using $\mathrm{P}$ that was unavailable to Eucalyptus (Binkley and Ryan, 1998; Binkley et al., 2000).

\section{Effects of species proportion at high $N$}

At high N, E. globulus growth was greater in EA compared to EE, but growth of $A$. mearnsii was lower in EA than AA. As a result, EE was more productive than EA because the greater E. globulus growth in EA did not make up for the reduction in $A$. mearnsii growth. Also, the amount of $\mathrm{N}$ in total pot biomass was highest in EE and lowest in AA. So $\mathrm{N}$ uptake increased with aboveground biomass rather than with the proportion of A. mearnsii. E. globulus had a higher $\mathrm{N}$ use efficiency and showed a greater growth response to $\mathrm{N}$ than A. mearnsii. Thus E. globulus appeared to have a competitive advantage at high $\mathrm{N}$ and was able to suppress A. mearnsii. However, this greater competitiveness of E. globulus only became apparent later in the experiment. Similar patterns were found by Boyden et al. (2005) who examined the inter- and intraspecific interactions between $E$. saligna and $F$. moluccana neighbours along gradients of $\mathrm{N}$ and $\mathrm{P}$ availability in a field trial. In that experiment the growth of the N-fixing $F$. moluccana was higher with $E$. saligna neighbours at low $\mathrm{N}$, but lower at high $\mathrm{N}$, where the competitive influence of E. saligna was higher.

\section{Effects of species proportion at high and low $P$}

The growth response to $\mathrm{P}$ was less pronounced than the response to N. A. mearnsii growth was not significantly higher in EA than AA at either high or low $\mathrm{P}$, however E. globulus grew larger in EA than EE at both levels of P. Furthermore the increase in E. globulus growth in EA compared to EE (as shown by RY of aboveground biomass) was higher at high P than low P. Similarly, Boyden et al. (2005) found that the growth of $E$. saligna trees increased with $F$. moluccana at high $\mathrm{P}$ but declined at low P. Similarly, Boyden et al. (2005) found that the growth of E. Saligna trees increased with $F$. moluccana increased with $\mathrm{P}$ addition in a pot trial (Binkley et al., 2003b). Phosphorus uptake in aboveground biomass was similar in EE, EA and AA, suggesting no limitation of $\mathrm{P}$ in any treatment. Similarly, the proportion of plant + soil $\mathrm{P}$ in plant biomass did not change in EE, EA or AA showing no evidence of resource differentiation for $\mathrm{P}$. Since E. globulus had a higher $\mathrm{P}$ use efficiency and a greater response to $\mathrm{P}$ fertiliser than $A$. mearnsii, E. globulus may have experienced less competition in EA than EE, especially at high $\mathrm{P}$ where $A$. mearnsii biomass production was lowest and E. globulus RY was highest.

The results also suggest that $P$ fertiliser may have increased $\mathrm{N}$ availability, either by influencing $\mathrm{N}$ mineralisation by soil microbes or the $\mathrm{P}$ uptake capacity of fine roots. For example, the soil $\mathrm{N}$ content was lower at high $\mathrm{P}$ than at low $\mathrm{P}$ indicating that more $\mathrm{N}$ may have been available and used by the plants at high $\mathrm{P}$ when compared to low $\mathrm{P}$. Increases in $\mathrm{N}$ mineralisation have been measured following the addition of $\mathrm{P}$ fertiliser to soils of several Eucalyptus forests (Bauhus and Khanna, 1994; Falkiner et al., 1993; Hossain et al., 1995). Alternatively, $P$ availability might influence rates of $\mathrm{N}$-fixation. For example Boyden et al. (2005) suggested that the higher growth of E. saligna with $F$. moluccana at high $\mathrm{P}$ but not at low $\mathrm{P}$ might have resulted from higher rates of $\mathrm{N}$-fixation by $F$. moluccana at high P. Rates of $\mathrm{N}$-fixation for $F$. moluccana increased with $\mathrm{P}$ addition in a pot trial (Binkley et al., 2003b).

\section{Implications for mixed-species systems}

The results of this experiment show that species interactions differ when there are differences in the availability of limiting resources. At all levels of $\mathrm{N}$ and $\mathrm{P} E$. globulus was larger in mixture than EE and this advantage (as shown by RY) was maintained or increased from low to high $\mathrm{N}$ or $\mathrm{P}$. Thus the positive interactions increased relative to competitive interactions for E. globulus 
in mixtures. However, for A. mearnsii, growth improved in EA when compared to AA at low N only and was unchanged or reduced in EA compared to $\mathrm{AA}$ at high $\mathrm{N}$ and at both levels of $\mathrm{P}$. Thus increases in $\mathrm{N}$ or $\mathrm{P}$ appeared to increase competition from E. globulus, which outweighed any positive effects of increased resource availability for A. mearnsii. Similarly, the success of certain mixed-species combinations in field trials has depended on site factors. For example the facilitative effect of higher $\mathrm{N}$ availability appears more likely to increase growth on sites where $\mathrm{N}$ is a major limiting resource (Binkley, 1992; Binkley and Green, 1983; DeBell et al., 1987; Khanna, 1997, 1998). On sites with low $\mathrm{N}$ availability, the N-fixing species Facaltaria moluccana, Alnus rubra and Lupinus arboreus increased the growth of Eucalyptus saligna, Pseudotsuga menziesii and Pinus radiata respectively (Beets and Madgwick, 1988; Binkley, 1983, 2003; Binkley et al., 1992b, 2003a; DeBell et al., 1987). However, the same species combinations were not successful (similar or lower productivity in mixtures than monocultures) on other sites where $\mathrm{N}$ availability was higher (Binkley, 1983; Binkley et al., 1992b) or the relative availability of other resources such as water and $\mathrm{P}$ were the major growth limiting resources (DeBell et al., 1987; Smethurst et al., 1986). When the interactions between species reduce the competition for a major growth limiting resource, mixtures are more productive than monocultures. When other factors limit growth, the different species will compete for those resources and competition will be stronger than facilitative or competitive reduction interactions.

These results emphasise the importance of appropriate site selection based on the interactions that are likely to occur in a mixture. Similar conclusions regarding the effect of site characteristics on the success of mixtures have been reached in other studies (Assmann, 1970; Boydon et al., 2005; DeBell et al., 1987; Fredericksen et al., 1993; West, 1991). In addition, it may be possible to increase the relative effect of the positive interactions in a mixture by relieving competition for resources that will not increase as a result of species interactions. For example, $\mathrm{N}$-fixing species may use more $\mathrm{P}$ than non-N-fixing species and may compete intensely for $\mathrm{P}$ when mixed with a non-N-fixing species (Marschner, 1988). Therefore the competition for
$\mathrm{P}$ may reduce the facilitative effect of higher $\mathrm{N}$ availability, particularly as the stand ages and more $\mathrm{P}$ is stored in the biomass. The addition of $\mathrm{P}$ fertiliser to a mixture containing a $\mathrm{N}$-fixer may therefore increase the growth of the mixture relative to a monoculture and maintain this effect as the plantation develops (Binkley et al., 1992a; Khanna, 1998). This pot trial demonstrates how an increase in the biomass production of E. globulus in mixture compared to monoculture can be further enhanced by adding P (as shown by RY). The additional $\mathrm{P}$ may not only reduce competition for $\mathrm{P}$ but may increase rates of $\mathrm{N}$-fixation (Binkley et al., 1992a, 2003b).

It is important to note that while a pot trial enables more control over experimental conditions than field trials, there are significant differences in the temporal and spatial aspects of such studies. Thus the results of this particular species combination cannot be directly extrapolated to field conditions. However, it can be assumed that similar interactions will occur in field situations when the availability of resources changes and, interestingly, the same species combination has been successful in several field trials (Bauhus et al., 2004; Forrester et al., 2004; Khanna, 1997; Samraj et al., 1977).

\section{Acknowledgements}

Forest and Wood Products Research and Development Corporation provided funding for this project (PG01.3102). David Forrester received a scholarship from the Cooperative Research Centre for Greenhouse Accounting. Thanks to Ljube Cvetkoski, Luke Wensing, Matt Forrester, Heather Forrester, Christine Donnelly and John Marsh for professional advice, help with statistical analyses, pot trial maintenance, data collection and lab work.

\section{References}

Assmann E 1970 The Principles of Forest Yield Study. Pergamon Press, Oxford.

Baker D D, Du D and Fried M 1994 Influence of combined nitrogen level and Eucalyptus competition on dinitrogen fixation in nodulated Casuarina. Protoplasma 183, 24-28.

Bauhus J and Khanna P K 1994 Carbon and nitrogen turnover in 2 acid forest soils of Southeast Australia as affected by phosphorus addition and drying and rewetting cycles. Biol. Fert. Soils 17, 212-218. 
Bauhus J, van Winden A P and Nicotra A B 2004 Aboveground interactions and productivity in mixed-species plantations of Acacia mearnsii and Eucalyptus globulus. Can. J. For. Res. 34, 686-694.

Beets P N and Madgwick H A I 1988 Aboveground dry matter and nutrient content of Pinus radiata as affected by lupin, fertilizer, thinning, and stand age. NZ. J. For. Sci. $18,43-64$.

Bertness M D and Callaway R M 1994 Positive interactions in communities. Trends Ecol. Evol. 9, 191-193.

Binkley D 1983 Ecosystem production in Douglas-fir plantations: Interaction of Red Alder and site fertility. For. Ecol. Manag. 5, 215-227.

Binkley D 1992 Mixtures of nitrogen-fixing and non-nitrogenfixing tree species. In The Ecology of Mixed Species Stands of Trees. Eds. M G R Cannell, D C Malcolm and P A Robertson. pp. 99-123. Blackwell Scientific, London.

Binkley D 2003 Seven decades of stand development in mixed and pure stands of conifers and nitrogen-fixing red alder. Can. J. For. Res. 33, 2274-2279.

Binkley D, Dunkin K A, DeBell D and Ryan M G 1992a Production and nutrient cycling in mixed plantations of Eucalyptus and Albizia in Hawaii. For. Sci. 38, 393-408.

Binkley D, Giardina C and Bashkin M A 2000 Soil phosphorous pools and supply under the influence of Eucalyptus saligna and nitrogen-fixing Albizia facaltaria. For. Ecol. Manag. 128, 241-247.

Binkley D and Green S 1983 Production in mixtures of conifers and red alder: the importance of site fertility and stand age. In USDA Forest Service General Technical Report PNW-163, Eds. R Ballard and S P Gessel. pp. 112-117. Portland, OR.

Binkley D and Ryan M G 1998 Net primary production and nutrient cycling in replicated stands of Eucalyptus saligna and Albizia facaltaria. For. Ecol. Manag. 112, 79-85.

Binkley D, Senock R, Bird S and Cole T G 2003a Twenty years of stand development in pure and mixed stands of Eucalyptus saligna and $\mathrm{N}$-fixing Facaltaria moluccana. For. Ecol. Manag. 182, 93-102.

Binkley D, Senock R and Cromack KJ 2003b Phosphorus limitation on nitrogen fixation by Facaltaria seedlings. For. Ecol. Manag. 186, 171-176.

Binkley D, Sollins P, Bell R, Sachs D and Myrold D 1992b Biogeochemistry of adjacent conifer and alder-conifer stands. Ecology 73, 2022-2033.

Bloom A J, Chapin F S I and Mooney H A 1985 Resource limitation in plants - an economic analogy. Ann. Rev. Ecol. Syst. 16, 363-392.

Boyden S, Binkley D and Senock R 2005 Competition and facilitation between Eucalyptus and nitrogen-fixing Falcataria in relation to soil fertility. Ecol 86, 992-1001.

Cannell M G R, Malcolm D C and Robertson P A 1992 The Ecology of Mixed Species Stands of Trees. Blackwell Scientific, London.

Cochran W G and Cox G M 1957 Experimental Designs. 2Wiley, New York.

DeBell D S, Whitesell C D and Crabb T B 1987 Benefits of Eucalyptus-Albizia mixtures vary by site on Hawaii Island. USDA For. Serv. Res. Paper PSW-187, 6 pp.

Falkiner R A, Khanna P K and Raison R J 1993 Effect of superphosphate addition on N-mineralization in some Australian forest soils. Aust. J. Soil Res. 31, 285-296.

FAO 1992 Mixed and pure forest plantations in the tropics and subtropics. FAO Forestry paper 103 (based on the work of $\mathrm{T} \mathbf{J}$ Wormald). Food and Agriculture Organization of the United Nations, FAO of the UN, Rome, Italy, $151 \mathrm{pp}$.

Forrester D I 2004 Mixed-species plantation of nitrogen-fixing and non-nitrogen-fixing trees. School of Resources, Environment and Society, The Australian National University, Canberra, pp 196 (http://thesis.anu.edu.au/public/adtANU20050202.164252/index.html).

Forrester D I, Bauhus J and Khanna P K 2004 Growth dynamics in a mixed-species plantation of Eucalyptus globulus and Acacia mearnsii. For. Ecol. Manag. 193, 81-95.

Fredericksen T S, Zedaker S M, Smith D W, Seiler J R and Kreh R E 1993 Interference interations in experimental pinehardwood stands. Can. J. For. Res. 23, 2032-2043.

Harper J L 1977 Population Biology of plants. Academic Press, New York.

Heffernan B 1985 A Handbook of Methods of Inorganic Chemical Analysis for Forest Soils, Foliage and Water. CSIRO Division of Forest Research, Canberra.

Holmgren M, Scheffer M and Huston M A 1997 The interplay of facilitation and competition in plant communities. Ecology 78, 1966-1975.

Hossain A, Raison R J and Khanna P K 1995 Effects of fertilizer application and fire regime on soil microbial biomass carbon and nitrogen, and nitrogen mineralization in an Australian Sub-Alpine Eucalypt Forest. Biol. Fert. Soils 19, 246-252.

Jolliffe P A 2000 The replacement series. J. Ecol. 88, 371-385.

Kaye J P, Resh S C, Kaye M W and Chimmer R A 2000 Nutrient and carbon dynamics in a replacement series of Eucalyptus and Albizia trees. Ecology 81, 3267-3273.

Kelty M J and Cameron I R 1995 Plot designs for the analysis of species interactions in mixed stands. Comm. For. Rev. 74, 322-332.

Khanna P K 1997 Comparison of growth and nutrition of young monocultures and mixed stands of Eucalyptus globulus and Acacia mearnsii. For. Ecol. Manag. 94, 105-113.

Khanna P K 1998 Nutrient cycling under mixed-species tree systems in southeast Asia. Agrof. Syst. 38, 99-120.

Marschner H 1988 Mineral Nutrition of Higher Plants. Academic Press, London.

Samraj P, Chinnamani S and Haldorai B 1977 Natural versus man-made forest in Nilgris with special reference to runoff, soil loss and productivity. Indian Forester 103, 460-465.

Smethurst P J, Turvey N D and Attiwill P M 1986 Effect of Lupinus spp. on soil nutrient availability and the growth of Pinus radiata D.Don seedlings on a sandy podzol in Victoria, Australia. Plant Soil 95, 183-190.

Vandermeer J 1989 The Ecology of Intercropping. Cambridge University Press, New York.

Vezzanni F M, Tedesco M J and Barros N F 2001 Alteracoes dos nutrientes no solo e nas plantas em consorcio de eucalipto e acacia negra. Rev. Bras. Cienc. Solo. 25, 225-231.

West G G 1991 Douglas fir, Japanese Larch and European Larch in pure and mixed stands. NZ. J. For. Sci. 21, 3-9.

Williams E R, Matheson A C and Harwood C E 2002 Experimental Design and Analysis for Tree Improvement. CSIRO Publishing, Melbourne.

Williams A C and McCarthy B C 2001 A new index of interspecific competition for replacement and additive designs. Ecol. Res. 16, 29-40.

Section editor: H. Lambers 